\title{
Methodical bases of selection and evaluation of the effectiveness of the projects of the urban territory renovation
}

\author{
Evgeniya Sizova ${ }^{1, *}$ Evgeniya Zhutaeva ${ }^{1}$, and Andrei Chugunov ${ }^{1}$ \\ ${ }^{1}$ Voronezh State Technical University, Moscow Avenue, 14, Voronezh, 394026, Russia
}

\begin{abstract}
The article highlights features of processes of urban territory renovation from the perspective of a commercial entity participating in the implementation of a project. The requirements of high-rise construction projects to the entities, that carry out them, are considered. The advantages of large enterprises as participants in renovation projects are systematized, contributing to their most efficient implementation. The factors, which influence the success of the renovation projects, are presented. A method for selecting projects for implementation based on criteria grouped by qualitative characteristics and contributing to the most complete and comprehensive evaluation of the project is suggested. Patterns to prioritize and harmonize renovation projects in terms of multi-project activity of the enterprise are considered.
\end{abstract}

\section{Introduction}

Renovation of urban areas as a complex integrated process is designed to adapt the existing territory and facilities to modern needs in order to increase economic, social, environmental efficiency and rational use of the territory as a whole. At present moment, the renovation is given special attention both by the state and by market actors. Companies are interested in implementing projects that are characterized by economic profitability and achievable planned results with optimal capacity utilization.

Problems of renovation of urban areas are discussed in [1,2]. The authors note that renovation is a multi-faceted process, requiring the participation of a large number of subjects, and that is characterized by high value of the results. Based on the works [3, 4], one can draw a conclusion about the main prerequisites for changing the current urban environment:

- Loss of objects of their functional qualities or initially inefficient functional specialization of buildings or territories;

- Lack of territory for new construction;

- a change in the entire urban environment, leading to the need for changes within specific territories;

- obsolescence and dilapidation of the existing funds;

- the need to preserve the territory of the historical center, objects of cultural heritage.

\footnotetext{
* Corresponding author: sizova@,vgasu.vrn.ru
} 
The questions on economic rationale of high-rise construction were considered in [5]. There was noted that the specifics of constructional solutions, as well as strict requirements for reliability and safety lead to a significant increase in project costs. However, the resulting increase in the rationality of the use of territories in terms of their limitation is an important aspect that makes high-rise construction in demand. Criteria for selection of investment projects to implement and evaluation of economic efficiency were considered in [6-10]. Based on the results of the literature review, it can be concluded that the question of selecting criteria for the evaluation of investment projects is one of the most important, but it has not been adequately reflected in the studies in terms of projects for urban renovation.

\section{Experimental part}

According to the established renovation procedure, an investment project is formed, before the procedure begins, which defines all types of the planned works. The analysis of the ways to select renovation projects precedes the identification of features, on which the composition of the project participants will depend, the coordination patterns, the sources and procedure for financing, and many other features.

The specific features of renovation projects, which must be taken into account when evaluating the efficiency of investment, include the following:

1. The presence of additional difficulties in the "working" objects in an already existing environment with the least damage (especially in densely built-up conditions) and the need to ensure the functional consistency of objects.

2. Uncertainty of the targets at the initial stages of the project.

3. Difficulties caused by the definition of the planning horizon for the project.

4. Uncertainty in the technical and economic evaluation of design decisions, caused by the unique nature of the objects and the non-reproducibility of the conditions, as well as the susceptibility to the influence of internal and external factors.

5. Strongly expressed public importance of projects.

6.There is a need to coordinate the interests of a significant number of participants, that are involved in the project, directly or indirectly (state and municipal authorities, owners, enterprises engaged in the renovation process, etc.)

In addition, renovation projects are characterized by restrictions on the timing of implementation, content, resources, and also ones require significant investment. Renovation projects, including the construction of high-rise, large-span and other unique buildings and structures or work of a large scale, bring special requirements on participating in projects organizations. Only large enterprises can fully meet these requirements. They have a set of characteristics that make them the most preferred subjects to implement renovation projects (Fig. 1). 


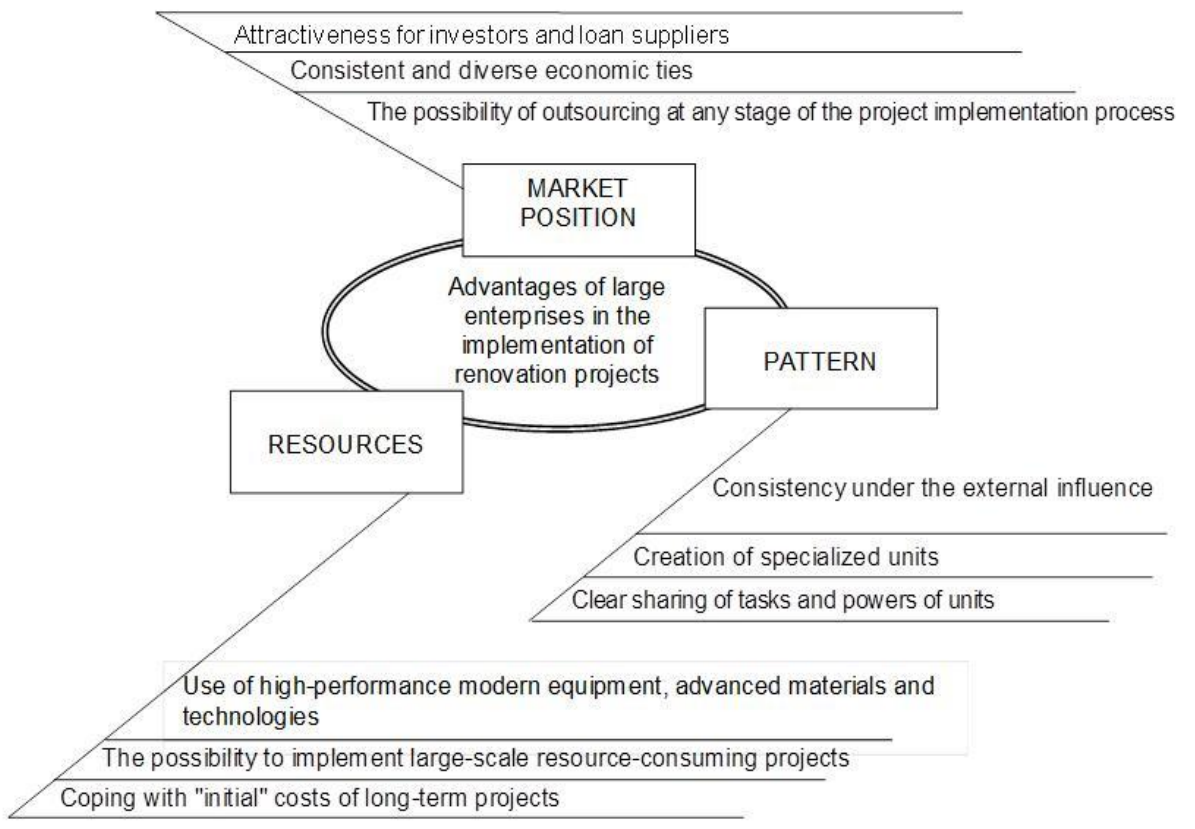

Fig. 1. Advantages of large enterprises in the implementation of renovation projects.

Large enterprises have significant resources to implement large-scale, high-risk, longterm projects. The significant expenses at the initial stages is offset by financial reserves and incomes in other branches, unlike small enterprises, which may not have reserves and capacities for similar projects. Significant revenue of large companies leads to an increased demand for scientific and technical developments, which allows achieving significant rates of return on the costs of their implementation

\section{Results}

Selection of projects to implement is an important stage for the enterprise, requiring a set of criteria that allow to comprehensively evaluate the project, while maintaining a certain level of materiality (priority) of the criteria. Based on the identified features of renovation projects and the factors that affect the efficiency of project implementation, with account of the advantages of large enterprises as participants in the implementation of renovation projects, and the peculiarities of projects for the construction of high-rise, large-span and other unique buildings and structures, the following system of criteria selection and evaluation of the effectiveness of renovation projects is suggested. The system of criteria is presented in general terms in Fig. 2. 


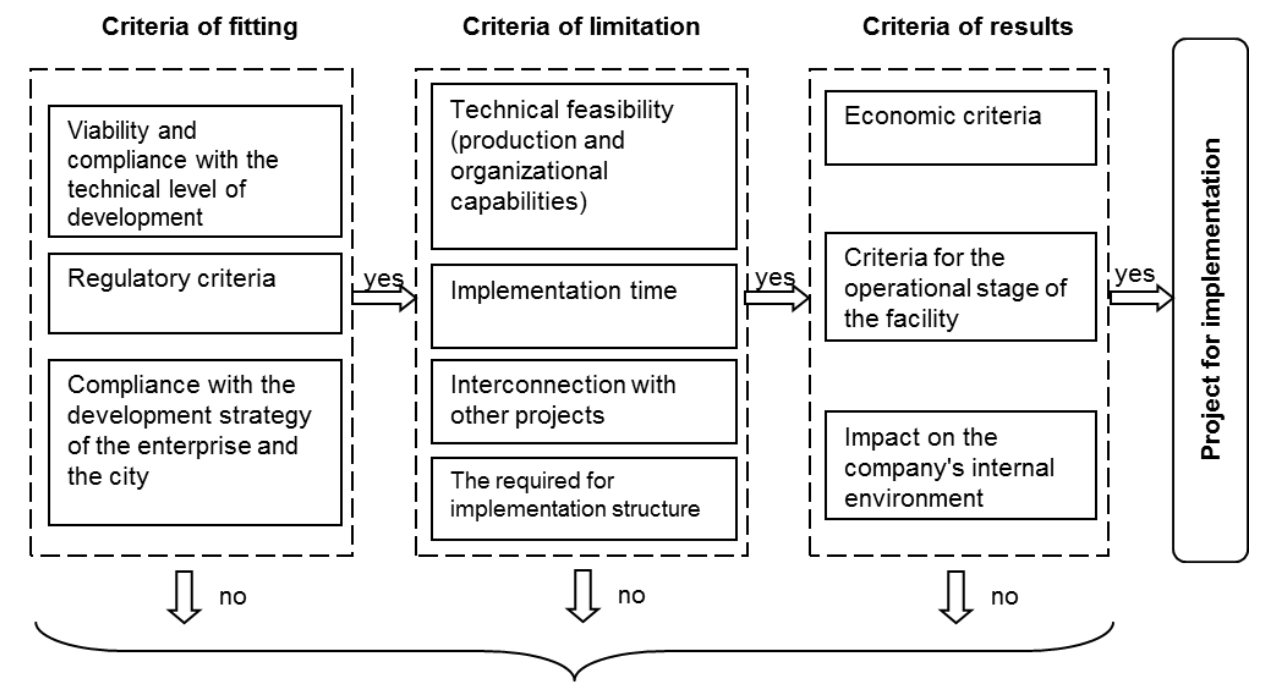

Project disapproval

Refinement of project

Project is postponed

Fig. 2. Criteria for selection of projects.

The criteria of fitting limit the range of renovation projects to those that satisfying the basic development vectors at the macro, meso and micro levels. The compliance of the project with the progressivity ratio at the global and national levels of technology development is checked, as well as the prospects and necessity for the city and for the enterprise itself. Compliance with regulatory requirements is evaluated. Methods for harmonizing existing and required ratio are considered, alternative regulatory sources are analyzed, and scales of forthcoming adjustments are evaluated since the implementation of projects with innovative technology solutions or individual elements is usually not envisaged in the existing normative documentation at the time of the project analysis.

The criteria of limitation relate to the conditions necessary for the implementation of the project. Since any enterprise has a limited potential for objective reasons, the project should be implemented within the available resources, as well as the correlations with projects that are already implemented for consistency, degree of dependence and the possibility of harmonization. The preliminary number of the entities, which are planned to be involved in the project implementation, are considered, including the possibility, if necessary, to attract external actors, their willingness to participate is evaluated, and the cooperation between them are contemplated. One of the most important criteria for limitation is the period of implementation. The fitting of the set deadlines is determined individually by the economic entity.

The criteria for the results relate to the set and objectively anticipated results of the project implementation. From the economic indicators, the following are traditionally calculated:

1. Payback period.

2. Net present value.

3. Project profitability index.

In addition, a plan of financial flows is drawn up, absolute costs, net profit, additional financing, interest payments and other indicators characterizing the results of the project in terms of money are estimated.

Moreover, the qualitative indicators of the operational stage of the facility are relevant to the result criteria, and the possible consequences for the internal environment of the 
enterprise that may entail the implementation of the project are anticipated. Such consequences include changes in the structure of the enterprise, the impact on the position and status of the enterprise in the market, the benefits that are obtained in the form of replenishing the knowledge base, increasing experience, etc.

The features of large construction companies allow implementing several renovation projects simultaneously. Multi-project workflow requires a special approach, since the company's objective is to optimally distribute its resources and time the deadlines with stages of implementation.

A lot of the projects under consideration on the principle of priority can be divided into priority and non-priority ones. Prioritizing (importance for a particular company) projects is a difficult task. The prioritizing process is exacerbated in large enterprises, that involved in the implementation of renovation projects, by the multidimensionality and diversification of their activities, as well as the significance of the project for municipality. Since, based on inherent features, the projects of any company are characterized by a variety of tasks, directions, characteristics, parameters, it is difficult to comprehensively describe its weight out of the context that determines the characteristics of the company. At the same time, prioritizing of projects can not be dwelled solely on complying with the list of priority vectors in accordance with the development strategy. Therefore, the company should independently be guided by the system of goals, objectives, development priorities at the time of the consideration of the project in order to set the priority. The prioritizing process for the renovation project can be described as follows (Fig. 3).

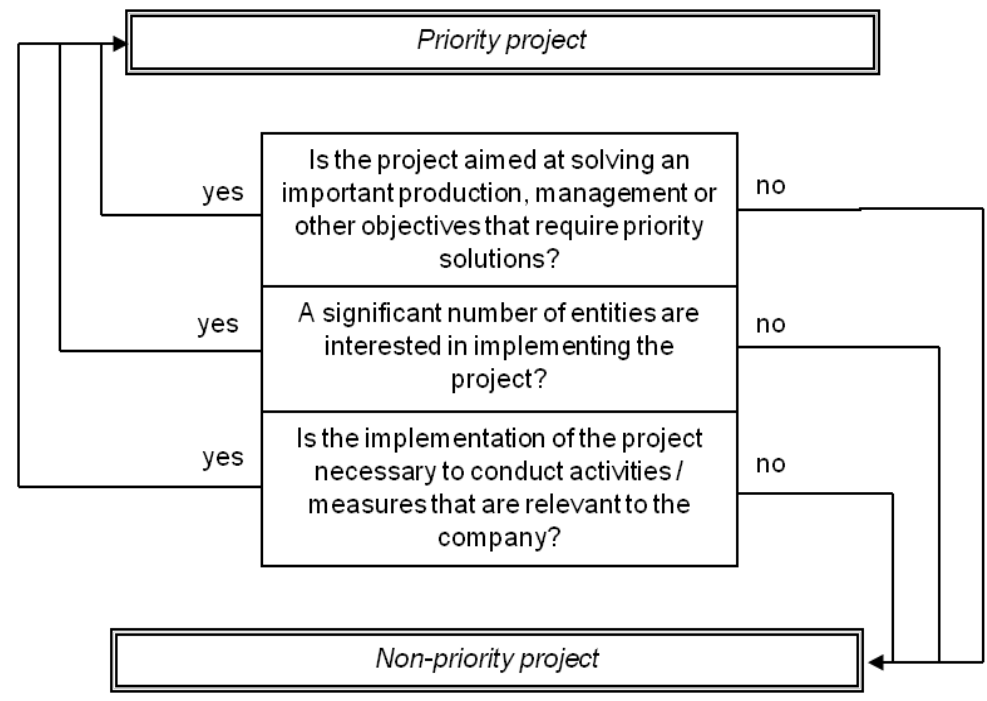

Fig. 3. Prioritizing the project.

The inconsistency and contradictions in the renovation projects implemented by the enterprise can lead to non-compliance with the terms of their implementation, budget overruns, results that do not meet the anticipations, as well as project closing. It is necessary to evaluate in advance the level and nature of the relationships between all projects under consideration, implemented and postponed ones in order to avoid these consequences,

From the authors' point of view, the dependence of renovation projects can be manifested in three aspects: resources, result and pattern.

Dependence on the outcome occurs in the case when projects should be implemented sequentially in accordance with their internal logic and characteristics, i.e. without 
executing one project (or its specific stage), there is no way to begin the implementation of the next one. This type of dependence results in two ways: firstly, the start and end dates for the implementation of the priority project affect the timing of the beginning of the subsequent interrelated one. Secondly, the qualitative and quantitative results, which are directly obtained at the output, can influence the requirements for the subsequent project or affect its principal components. Dependence on the structure is the requirements for the participants involved in the implementation of the renovation project. Dependence of projects on resources (labor, material, technical and other resources that are necessary for different projects) is coordinated through the implementation of a number of traditional activities for project management (identification of needs, scheduling, assessment of labor reserves, etc.) using tools for production, distribution and financial logistics, as well as methods of managing human capital assets

\section{Discussion}

Despite the adopted at the enterprise patterns for selection renovation projects, there are a number of factors that affect the success of the project. From the position of the commercial entity, the following factors can be distinguished:

1. Nature of interaction with state and municipal authorities.

2. The degree of influence on the implementation of the project of existing regulatory framework and regulatory documentation in the field of renovation and construction.

3. Presence and possibility to overcome administrative barriers in project implementation.

4. Reliability and stability of funding sources.

5. Organizational structure of the enterprise, as well as individual features of economic activity (methods of work, qualification of personnel, etc.).

6. The level and nature of cooperation and integration with other participants in the life cycle (general contractors/subcontractors, suppliers of building materials, designers, etc.).

7. Previous experience in the implementation of renovation projects.

It is also necessary to take into account the complexity of accurate prediction in the process of selection and implementation of projects in a number of cases, since renovation projects are characterized by long terms of implementation.

\section{Conclusion}

To date, the specifics of activities for the implementation of urban renovation projects is determined not only by industry aspects, but also by the scale of activities. Based on the capital intensity and the need to overcome barriers, the most preferred participants among the business sector will be large enterprises that have an optimal, well-designed and coordinated pattern for selection of projects with account of its own features. Successfully implemented projects on the renovation of the territory will encourage to use the urban development potential fully and increase the utility level of territories and enhance the overall competitiveness of the municipal.

\section{References}

1. E.A. Karaulanova, I.V. Kukina, Molodyozh' i nauka, 1-3 (2011)

2. A.S. Vilkova, D.V. Marennikova, Mezhdunarodnyj nauchno-issledovatel'skij zhurnal, 6(6), 155-159 (2017) 
3. L.V. Tolstoj, R.G. Abakumov, Innovacionnaya nauka, 1,100-103 (2017)

4. A.K. Orlov, G.A. Smirnov, Ekonomika i predprinimatel'stvo, 10-3 (75-3), 510-513 (2016)

5. D.H. Ajbazova, Ekonomicheskie nauki, 138, 36-39 (2016)

6. S. Uvarova, S. Belyaeva, L. Myshovskaya, IOP Conference Series: Earth and Environmental Science, 90(1), 012169 (2017)

7. K. Gumba, S. Belyaeva, IOP Conference Series: Earth and Environmental Science, 90(1), 012163 (2017)

8. S. Belyaeva, D. Voronov, S. Erypalov, MATEC Web of Conferences, 106, 08033 (2017)

9. K. Gumba, S. Uvarova, S. Belyaeva, S. Revunova, MATEC Web of Conferences, 106, 08023 (2017)

10. A. Bukreev, O. Vasilyeva, V. Vlasenko, E. Sizova, MATEC Web of Conferences, 106 (2017) 